\title{
Storytelling: Fenômeno da Era da Liquidez
}

\author{
Adenil Alfeu DOMINGOS \\ (UNESP-Bauru)
}

Resumo: Pretende-se abordar aqui o storytelling como fenômeno de comunicação da era da liquidez. O objetivo é entendê-lo como um instrumento de ação da linguagem sobre sujeitos, nas esteiras de Salmon. Trata-se de uma máquina de fabricar e formatar pensamentos. Ao ultrapassar a simples informação, o storytelling tornou-se um discurso persuasivo, levando o receptor a repensar suas crenças e hábitos. Na mídia, assim, toda boa história tornou-se, rapidamente, um fenômeno de transtorytelling e até cursos de produção de narrativas para a mídia começam a pulular pelo país.

Palavras-Chave: storytelling; comunicação, marketing,

Abstract: There intends to board here the storytelling as phenomenon of communication of the era of the liquidity. The objective is to understand it like an instrument of action of the language on subjects, in Salmon's mats. It the question is a machine of manufacturing and formatting thoughts. While exceeding the simple information, the storytelling became a persuasive speech, taking the receiver to rethink his beliefs and habits. In the media, so, any good history became, quickly, a phenomenon of transtorytelling and up to courses of production of narratives for the media they are begun to spread by the country.

Keywords: storytelling, communication, marketing

\section{Introdução}

Esta pesquisa nasceu após a leitura do livro Storytelling: a máquina para fabricar histórias e formatar os espiritos, de Christian Salmon (2007). Notamos, então, a fecundidade desse tema e passamos a ler outros textos sobre ele. Até mesmo textos com assuntos paralelos, como o de Nelly Buonanno (2007) que trata do teledrama, como sendo um sistema contemporâneo de narrar história da sociedade italiana, tendo a televisão como supernarradora. Buonanno trata da 
explosão dos sucessos das histórias de ficção feitas em casa, que se firmaram no horário nobre dos principais canais, vencendo a competição dos importados americanos, desde as duas últimas décadas do século passado. Assim, a cultura de nicho, possuidora de um grande número de marcas pequenas, passa a conviver e competir com a cultura hit, ou seja, a de produtos com pequeno número de marcas, mas grande número de consumidores, segundo a teoria da Cauda Longa (ANDERSON, 2006). Para esse autor, as transações online permitiram que o custo de produção e distribuição de produtos fosse sensivelmente reduzido, ao massificar produtos em um único formato e tamanho para diferentes consumidores. Dentre esses produtos, estão os pacotes de storytellings com todas as nuanças de fenômeno da comunicação, entendemos nós.

Percebemos, então, a importância do ato de narrar histórias na mídia atual como um corpus de estudo para os meios universitários, principalmente para os Cursos de Letras e Comunicação. Vimos que se tratava de um fenômeno da era pós-moderna em que a comunicação sofre pesada influência da tecnologia e, dentro desse panorama, a narrativa ganha novas funções e isso deveria ser pesquisado cientificamente. Percebemos, também, que o processo de semiose de dada narrativa, tida como uma história exemplar, tornou-se uma fonte fértil de lucros para muitos intermédia, bem como aos midiadores e midiatários, ou seja, equipe de produção e público-alvo, respectivamente. Percebemos, ainda, que uma boa história provoca uma expansão horizontal de textos, em diferentes mídias, em diferentes linguagens, e suportes diferentes. Isso gera o que está sendo denominado de transtorytelling, como um movimento multi e trans e até mesmo intramedia. Assim se dão, por exemplo, reedições de programas na mídia com os mesmos temas, mas com linguagens diferentes.

\section{Storytelling e Transtorytelling}

De modo geral, os storytellings dão sentido ao mundo do homem, de diferentes modos, em diferentes épocas, em diferentes suportes, desde os primórdios até hoje, quando elas passaram a existir nos écrans como narrativas digitais (podcasts, webcams, blogs, televisão interativa). Não só as narrativas existentes são inumeráveis, como são inumeráveis os seus tipos, bem como as suas funções. Assegura-nos Roland Barthes (1971, p. 20): 
A narrativa está presente em todos os lugares, em todas as sociedades; não há, em parte alguma, povo algum sem narrativa; todas as classes, todos os grupos humanos tem suas narrativas, e freqüentemente estas narrativas são apreciadas por homens de cultura diferente, e mesmo oposta: a narrativa ridiculariza a boa e a má literatura: internacional, transhistórica, transcultural, a narrativa está aí, com a vida.

Os storytellings vão da simples blague à narrativa ficcional ou à informação noticiosa. Narrar é reviver, ou seja, produzir um storytelling revival, assegura-nos Salmon (2007, p. 14). Para esse autor, as narrativas pertencem às grandes categorias do conhecimento das quais nos servimos para compreender e ordenar o mundo. Na verdade, nosso pensamento só se fez por meio de narrativas. Elas são ideologicamente construídas com o objetivo do narrador interagir com seu narratário.

Quem nos alertou sobre o transtorytelling foi a leitura que fizemos dos textos de Maurício Mota (2007). Ele nos mostra como uma boa história - ex., a série de TV Smallville, que se originou nas histórias em quadrinho do Superman e já se encontra em $7^{\mathrm{a}}$. temporada gera outras, como a série Heroes, aparecida em 2006, que narra, em estilo quadrinhos, história de pessoas comuns que descobrem ter habilidades especiais e procuram salvar a Humanidade. As boas histórias se tornaram verdadeiros Midas, não só para a mídia em geral, mas até para certas empresas que comerciam bonecos, adereços e até vestimentas desses heróis. As personagens dessas narrativas, em geral, tornam-se celebridades e particularidades de suas vidas privadas passam a ser mostradas com intensidade na mídia, principalmente em periódicos destinados a essa finalidade, como a Revista Caras, da Editora Abril, por exemplo. Há ainda storytellings que são uma espécie de autopublicidade da própria empresa que as veicula, como, por exemplo, o Programa do Faustão da Rede Globo, que faz das histórias de vidas dos artistas, contratados pela Globo, um dos temas centrais do seu programa.

Mota (2007) assegurou, ainda, que os mestres no desenvolvimento de estruturas transmedia foram os japoneses, já nas décadas de 60/70. Hoje, existe até um núcleo do MIT (Massachusetts Institute of Technology) chamado Cool Japan preocupado em analisar 
toda a estrutura de entretenimento e distribuição de ativos pops para o governo japonês em parceria com Harvard. Assegura-nos Mota, ainda, que no transtorytelling não está em pauta apenas a intimidade com as outras mídias e, sim, o quanto a história cabe e se desdobra nelas. É preciso, então, "aprender a criar histórias incríveis e consistentes o bastante, não só para aplicar transversalmente como também para atrair marcas e veículos consolidados que precisam de envolvimento com os espectadores".

Assim, o storytelling é um fenômeno típico de marketing de nossa era, em que tudo se transforma em produto à venda, como vemos no depoimento abaixo de do diretor de Transmedia do Heroes, Mark Wardshaw.

Nós criamos os produtos transmedia envolvendo todos os roteiristas da série para a TV e temos pessoas que depois aprofundam o que foi decidido para a internet e celular. E a gente faz isso simplesmente por que aumenta a audiência da série dentro e fora da TV, agrada as marcas que querem inovar e viabiliza os episódios que custam 5 milhões de dólares em média. Ou a gente tinha liberdade para sentar com as marcas e os roteiristas juntos ou não tinha cabimento fazer o site de uma série com um tema tão universal. $O$ tema não pode se esgotar na TV. E as marcas precisam dizer pra gente o que querem diretamente. O briefing sozinho, dizendo comunicação 360 é o mesmo que nada.

Mota (2007) explica que há empresas de ponta investindo em projetos de storytelling. São empreendimentos que vão desde o patrocínio de downloads, spots de 30', antes das reprises online, até uma promoção nacional de criação de novos personagens para a série Heroes. Esse mercado de narrativas explorado pela mída é que estamos tratando neste artigo como sendo storytelling. As narrativas permitem ao homem não só memorizar o passado, ressignificando-o em busca de efeitos de sentido, como também servem para projetar o futuro, de modo telelológico.

\subsection{Storytelling: conceitos amplo e restrito}

Se narrar é um ato ancestral, a narração, como ato intencional humano, é antropocêntrico. Isso criou um homem ideal, como herói 
das suas próprias aventuras. $\mathrm{O}$ ato de viver em sociedade foi necessário à sobrevivência da espécie. Saber narrar é um meio de sobreviver, ou seja, um meio de apanhar uma presa ou de se afastar do predador, assim como serve para conquistar o parceiro sexual. Portanto, sob as narrativas estão nossos mais recônditos instintos. $\mathrm{O}$ homem, desse modo, não é só criador da sua própria história, como se tornou também sua criatura; ele não só foi produzido dentro da história milenar que definiu o homem como ser cultural, tirando-o do seu nicho natural, como também permitiu pinçar entre todas as histórias de vida aquelas que deveriam ser notícia ou não.

$\mathrm{Na}$ narrativa da história da humanidade, o homem é visto como um ser semelhante a um deus que ex-plica o mundo ao usar linguagem: o prefixo "ex" coloca o homem do lado do fora do processo de comunicação natural, como um olho privilegiado que consegue "plicar", criar dobras, como o deus-verbo que usa palavras para criar mundos, no gênese bíblico. Ao criar a narrativa do deusverbo, como imagem e semelhança humana, tudo se antropomorfiza. Desse modo, o homem deixou de se sentir holisticamente im-plicado no todo da comunicação cósmica, para se tornar um ser produtor e produzido pelos signos da linguagem que ele mesmo criou. $\mathrm{O}$ homem é um discurso, um grande simulacro pensando a si mesmo e, paradoxalmente, sendo pensado e analisado por si mesmo.

Em sentido amplo, portanto, o storytelling não é uma novidade absoluta. É a antiga arte de transmitir fatos, reais ou ficcionais, em diferentes tipos de suporte, de modo verbal ou não, a fim de emocionar e informar grandes públicos e até gerações. São histórias esculpidas em suportes efêmeros, como a oralidade de sons articulados ou não; ou a impressão de idéias na areia das praias; ou, ainda, aos mais duradouros, como os rabiscos ou pinturas nas paredes das cavernas; ou mesmo passando pelas tatuagens na pele narrando histórias condensadas em uma simples cena narrativa que provoca um antes e um depois; conseguimos, assim, chegar à geração das imagens eletrônicas virtuais nos écrans do computador. Não há nada, enfim, que não seja uma "ex-plicação" como narrativa de um acontecimento qualquer, em que "ex" é colocar-se fora e "plicar" é criar mundos pelas palavras.

No sentido estreito, porém, storytelling é a atualização do potencial do fenômeno do marketing da era pós-moderna 
multimidiática com diferentes objetivos pragmáticos. Um deles, por exemplo, é servir como um meio de alcançar o poder. "Sem uma boa história, não há nem poder, nem glória”: eis o lema pós-moderno dos homens de marketing, empresários, políticos e até anônimos que narram histórias com o objetivo de conquistar poder e fama na sociedade atual. Com elas, via Internet, ou outra mídia qualquer, pessoas comuns podem virar celebridade da noite para o dia.

É o caso do blog de Bruna Surfistinha, visitado diariamente por milhares de internautas. As histórias picantes nele narradas geraram um livro em 2005, lançado pela desconhecida editora Panda Books, do Jornalista Marcelo Duarte, com o título de "O doce veneno do escorpião: diário de uma garota de programa", referindo-se a uma tatuagem existente no dorso da narradora. Rapidamente, esse livro entrou para a lista dos mais vendidos no país. O tema das narrativas dessa garota da classe média foram seus casos amorosos. Esse livro não só the deu fama, como lhe rendeu altos cachês. Bruna foi entrevistada em diferentes canais das grandes redes de TV, como "Programa do Jô", de Jô Soares, na Globo; "Superpop", de Luciana Gimenez, na Rede TV; e "Boa Noite, Brasil", de Gilberto Barros, na Bandeirantes. Seu livro foi notícia em quase todos os grandes jornais e webjornais brasileiros. Surfistinha tomou sua vida de ex-prostituta e nela encontrou um tema de interesse da grande massa. Assim, o storytelling transforma sujeitos desconhecidos, mas que têm uma boa história para contar em personalidades e relatos banais em grandes sucesso de público, ou seja, em grandes fontes de renda.

\section{Internet e Storytelling}

Jamais se contou tantas histórias para platéias tão numerosas, nem se teve tanto conhecimento sobre histórias de vida de outras pessoas como as encontradas, atualmente, na Internet. Na verdade, suas raízes são mais profundas, já que as novelas do rádio do século passado foram embriões novelas de Tv, que ora misturam fantasia e história real. Não é por acaso que os redatores de novelas procuram na vida real, muitas vezes até mesmo por meio de pesquisa, a temática a ser enfocada em suas narrativas. A rapidez de interação proporcionada pela Internet, como um espaço virtual infinito e de baixo custo para ser explorado como suporte de mensagens, além de 
ser até certo ponto democrático e quase sem censura, permitiu aos narradores de histórias uma liberdade ímpar de atuação. Ela permitiu, por exemplo, a existência de cibermuseus históricos onde quem quiser pode narrar a própria vida. Karen Worcman, uma das fundadoras do Museu da Pessoa, nas últimas décadas do século passado, no Rio de Janeiro, coordenou o projeto de História Oral, "Heranças e Lembranças", com o objetivo de conservar os depoimentos dos imigrantes judeus dessa cidade. Além da emoção que as narrativas provocaram nos leitores, bem como da percepção do rico valor dos depoimentos, o impacto foi positivo e imediato. Ele gerou o projeto "Memória em Rede" que, atualmente, espalha-se pelo mundo, tendo sido implantado em Portugal, Estados Unidos e Canadá. Seu objetivo é permitir que toda e qualquer pessoa possa ter sua história preservada. Cada depoimento torna-se, assim, uma fonte diferenciada de informações para a construção da "memória social" de certas comunidades com pluralidade de pontos de vista.

Projetos como esse pode provocar uma transformação fundamental na própria história oficial de um país, como o Brasil, por exemplo. É que o ponto de vista da nossa história oficial, até então, estava centrado no homem branco culto, da elite e, em geral, descendente de europeu. Essa elite, detentora do poder econômico, passou a ter o poder de impor idéias pelos grandes mídias, até mesmo ao subvencionálos, principalmente por meio da publicidade. Assim, a existência da Internet como um suporte de fácil acesso, se ainda não democratizou por completo o storytelling, dando vOz a todos os narradores saídos das classes menos privilegiadas, está permitindo, a quem queira, criar seus storytellings, demolindo preconceitos. Quase todos podem, portanto, compartilhar, com certa facilidade, de aventuras, lugares e situações sociais diversos, com a liberdade de alcançar amplos horizontes, como jamais a história da comunicação humana conheceu antes.

Multiplicam-se, então, diariamente, meios que permitem às pessoas inserirem-se na rede da Internet, fazendo narrativas, reais ou ficcionais, da própria vida ou de outras. São flogs ou fotologs narrando festas, viagens, encontros, como se fosse um diário virtual; blogs ou weblog, páginas da $W e b$ cujas atualizações chamadas posts podem possuir textos que pertencem, ou não, ao mesmo gênero textual, referirem-se ao mesmo assunto, ou não, serem escritos pela mesma pessoa, ou não; 
o Orkut, uma rede virtual de relacionamentos dos chamados orkuteiros foi iniciado em 2004 e já conta, hoje, só no Brasil, com mais de 23 milhões de filiados; os vídeos de festa jovens, de pessoas tentando expressar seus dotes como cantar ou dançar, filmes e composições amadoras de músicas de nicho multiplicam-se no Youtube. Fundado em 2005, o Youtube é um site na internet que permite que seus usuários carreguem, assistam e compartilhem vídeos em formato digital; há ainda meios não tão populares como o Facebook que, além de permitir veicular ilimitadas fotos há uma opção chamada My Privacy, que permite determinar quem pode ver seus dados, além de permitir compartilhar textos, importados de um blog, por exemplo; o Myspace que narra histórias de vida, sendo uma rede interativa de fotos, blogs e perfis de usuários; o Second Lyfe que permite ao narrador criar avatares de si mesmo e viver aventuras que não são possíveis na vida real, como se ele fosse o herói de um texto ficcional, feito de imagens de uma vida feita de símbolos virtuais. Os Podcasts que trazem as narrativas pessoais através da linguagem sonora, semelhante à radiofonizada.

\section{A era da liquidez de Bauman}

Qualquer narrador de histórias que insira seus textos na mídia pode idealizar à sua frente uma multidão sequiosa de boas histórias e conseguir aplausos, fama e até muito dinheiro. Ter uma boa história para contar é um caminho certo para se tornar personalidade. Mesmo que haja um revisor de textos por detrás ou uma equipe de pesquisadores fazendo investigações, como é o caso de jornalistas que passaram a se dedicar a recuperar dados e fatos de pessoas que tiveram uma vida a ser pinçada e transformada em storytelling midiático. É esse boom de narrativas na mídia que nos motiva a fazer essa pesquisa, na tentativa de entender melhor esse fenômeno.

A tecnologia atual, portanto, está permitindo à grande massa uma especularidade: mostrar-se e se ver, ao mesmo tempo, por meio da mídia. Como é normal ao ser humano projetar-se em um herói de uma narrativa qualquer, essa identificação justifica a explosão dos storytellings modernos. A intermedialidade nos permite hoje que não só assistamos ao espetáculo midiático da vida como narratários, mas também, que participemos dessa explosão como narradores. A vida, assim, se torna um grande espetáculo midático e flui sem limites e sem 
compromissos sólidos. Vivemos como se estivéssemos dentro do grande palco da vida, representando dezenas de papéis e vestindo infinitas máscaras, como uma segunda vida: a do discurso virtual. Esse fenômeno tem embaçado os limites do real e do mundo virtual.

O storytelling é um fenômeno afeito a essa era pós-moderna, pois é mais abrangente do que o simples ato ancestral de contar histórias reais ou ficcionais da humanidade; trata-se de um ato de tentativa de inclusão, político social e econômico, como um criadouro de heróis, embora meteóricos e olimpianos; trata-se do desmoronar da ilusão que só certas elites possam governar o mundo. Podemos, hoje, assistir à ascensão de um ator de Hollywood a governador dos Estados Unidos, como é o caso de Ronald Reagan, ou de Arnould Alois Schwarzenegger, ex-fisiculturista e ator, ora governador do estado da Califórnia; trata-se, também, do favorecimento do onírico, do fantasioso e espetacular, portanto, do predomínio do emocional sobre o lógico, que permite diálogos e informações mais humanizados entre as pessoas; trata-se, também, de um fenômeno de marketing, por um lado, e, da substituição da verticalidade para a horizontalidade de pensamento, de outro. Assim, o storytelling permite que tanto o sujeito narrador como o seu receptor sejam conduzidos a um ambiente quase impessoal, praticamente sem censura ou crítica, cujo julgamento fica por conta do interesse do público, em conhecer o tema ora explorado. Trata-se, enfim, de um mundo em que os limites entre ser e estar são nebulosos e fluidos.

Por isso, o storytelling será entendido aqui como o discurso que caracteriza a "era da liquidez", expressão do sociólogo Zygmunt Bauman (2004), para tratar a era da pós-modernidade. Para ele, a fluidez do que nos evolve na contemporaneidade, como, por exemplo, os valores morais, enfraqueceram-se em sua coerência. Vivemos a era dos contratos de pouca duração que são desfeitos e transformados com facilidade. Como todo contrato não deixa de ser uma narrativa, contratar e desfazer contratos, como os amorosos, tornou-se uma das características dessa nossa era. Assim, o próprio casamento, por vezes, tornou-se aberto, ficcional e metamórfico. Muitas das conquistas amorosas entre são tramadas online, de modo virtual. Nelas, quase não há mais a romântica idéia de amor eterno e único, com final feliz ou não, como no século XIX. Essa idéia foi substituída pela de ser infinita apenas enquanto dure, idéia que vai, cada vez mais fincando 
raízes na sociedade. A facilidade dos diálogos virtuais permite encontros de pessoas das mais diferentes regiões do globo em tempo praticamente real. Eis um dos motivos que estão proporcionando namoros e casamentos acertados em agências matrimoniais, ou programas de TV, por exemplo.

Alastra-se, assim, o interesse pela vida particular do outro e de expor a sua própria vida; os livros investigativos, sobre a vida de personalidades, como jogadores de futebol, por exemplo, ganham as páginas dos livros reportagens, para depois virarem filmes ou séries da TV, gerando, conseqüentemente, muita matéria para a mídia crítica. Tudo isso sem contar o grande número de livros sobre ajuda pessoal, narrando experiências de pessoas como exemplos de vida. Assim, a exposição da vida a grandes públicos parece ter banalizado não só a conquista e o relacionamento amoroso, mas também a vida em si mesma. Existem até revistas especializadas em comprar boas histórias a serem publicadas, de modo a produzir bons lucros.

Quase todo narrador de histórias, enfim, tem encontrado na mídia uma porta para adentrar e tornar-se conhecido de grandes públicos. Ilusoriamente, são possibilidades de sair do anonimato, de se sentir um herói, ou autor-herói, e se postar entre nomes consagrados pelo público, já que o processo está sendo vulgarizado e massificado. Só o site Roda de Histórias ${ }^{1}$ traz mais de cem indicações de outros que têm como tema a arte de contar histórias. A Internet, desse modo, passou a dar poder e voz às grandes massas, para que quase todos possam narrar e também serem narrados.

Essa democratização atingiu até certos profissionais da mídia. Os jornalistas, por exemplo, criaram seus sites na Internet, onde narram histórias e informam fatos, sem os mesmos compromissos institucionais clássicos, como a censura de um editorial. Esse tom confidencial do diálogo que a Internet permite, não só tornou a informação mais humana, viva e atraente ao grande público, como permitiu ao narrador do informado isentar-se dos compromissos jurídicos atrelados à ética do profissional jornalística de revelar apenas a verdade.

\footnotetext{
${ }^{1}$ Acesso pelo endereço: <http://www.rodadehistorias.com.br/sites.asp>. 


\section{Storytelling: o marketing pessoal}

O ex-presidente dos Estados Unidos (de 1981 a 1989) Ronald Reagan, ex-ator de cinema e ex-locutor de rádio, conquistou a simpatia dos norte-americanos, por ser um exímio contador de histórias. Ele evocava episódios de filmes de guerra como se a ficcionalidade deles pertencesse à história real de seu país. Segundo Salmon (2007, p. 9), o período de narrative turn, depois de conquistar a Casa Branca, nas últimas décadas do século passado, invadiu o mundo dos negócios, as ciências sociais, o universo da internet e até mesmo as próprias identidades pessoais.

Os meios de se popularizar em campanhas políticas ultrapassam hoje os showmícios e bottons para chegar à mídia escrita, radiofônica e televisada para atingir comunidades em rede na mídia online. É a era do marketing pessoal, na sociedade espetacularizada. O candidato a cargos políticos deixou de ser uma pessoa competente para governar, para ser quase que uma simples criação de marketing, uma personagem idealizada e, dentro suas características principais, está o fato de saber e usar boas narrativas.

As narrativas de marketing próprio praticadas em campanhas eleitorais têm apenas mostrado os aspectos positivos dos candidatos, assim como as grandes marcas idealizam seus produtos à venda. $\mathrm{O}$ marketing político quase não trata mais de exaltar as virtualidades administradoras desses candidatos, mas a de construir personas, como heróis onipotentes, para atuar nas mídias. Trata-se da produção do político "superstar", ou "hiperespetacular", para usarmos o termo de SUSCA (2007). Se, na era do rádio, o microfone deu extensão e potência à voz desse herói, atualmente, a TV maquiou o candidato para que ele se apresentasse ao grande público, dando extensão e importância ao detalhe físico, ao gesto, à vestimenta. No Brasil, Fernando Collor de Mello é o grande protótipo dessa era, pois se tratava do mocinho bonito, que usava camiseta, fazia cooper e caçava marajás.

Por sua vez, o advento da Internet não só ampliou todos esses pormenores como abriu espaços a diálogos intimistas entre candidato e eleitores. A Folha Online de 09 de agosto de 2006, por exemplo, divulga uma entrevista com o professor de redes Convergentes, Carlos Botessi da Unicamp, ao colunista Nelson de Sá, em que o entrevistado narra a história de como uma proposta simples 
de governo como "resgatar a dignidade dos animais de rua", feita por um candidato a vereança de Campinas, via on-line, é profícua. Isso deu a ele uma comunidade de eleitores formando uma rede de conexões na Internet e o tornou o mais votado dos candidatos. Botessi quis mostrar como as redes formadas em comunidades na Internet hoje são de fundamental importância, não só na divulgação de idéias políticas, como para qualquer cidadão narrar suas histórias.

\section{Storytelling: uma narrativa pragmática}

Entendemos storytelling como uma narrativa pragmática, ou seja, como o poder de uma ação interativa e relativa a negócios entre sujeitos. Trata-se de dar à narrativa uma função persuasiva, já que seu objetivo primeiro não é propriamente de informar um conteúdo, mas de "formatar espíritos", segundo Salmon. Esse processo está se espalhando para vários setores da vida social. No Brasil, temos o caso do atual presidente da República, Luiz Inácio da Silva. Ele tem se especializado em narrar sua história de vida como exemplo de herói vencedor e criar eventos para se mostrar na mídia. Ao estilo Color, ele chegou até mesmo jogar bola com seus correligionários com a camisa de um time de grande popularidade: o Corinthians. Ele tem se servido da sua origem humilde e pobre de nordestino para mostrar a sua capacidade de superação, como exemplo àqueles que se sentem injustiçados e reclamam do estado de miserabilidade que se encontram. Essa artimanha não só consegue desviar a atenção do povo dos problemas mais sérios da economia do país, dos impostos elevados, da educação deficitária, do salário mínimo de fome, da violência urbana e assim por diante, para torná-lo o grande herói de um país "realmente" democrático. É o próprio aedo acentuando que a sua vida é um exemplo para todos acreditarem no país. Há pouco, por exemplo, para justificar a mudança de rumo do Rio São Francisco para irrigar terras áridas do nordeste brasileiro, o presidente narrou fatos de sua vida de adolescente, quando, então, precisou carregar água em uma vasilha para usá-la em sua casa. Assim, a maior camada populacional do Brasil identifica-se com ele e torna-se seu fiel eleitor e defensor. Ele, então, projeta-se no cenário político do país, tendo como sustentáculo essa grande massa de eleitores menos favorecidos pelo sistema. A narrativa de sua vida passou a ser uma estratégica para ser entendido por essa massa e de 
convencer o povo a segui-lo e a imitá-lo. Suas narrativas não só criam uma empatia entre ele e quem a ouve, como também o qualifica como grande exemplo de herói vencedor.

Assim também, grandes empresários passaram a contar histórias, das suas trajetórias de sucesso para motivar seus empregados. É o caso, por exemplo, da vida de sucesso e empreendedora do Comandante Rolim. Rolim Adolfo Amaro nascera em 1942, em Pereira Barreto, interior do estado de São Paulo, onde passou parte de sua infância em casa de sapé, sem luz e banheiro. Ele iria se tornar um dos empresários mais bem sucedidos do país, ao fundar uma empresa, em 1961, a TAM (Táxi Aéreo Marília, cidade onde ora residia), ao perceber a necessidade de comércio de transportes aéreos regionais. Se, em 1971, a TAM transportou 3.000 passageiros, no ano 2000 ela atingiria a incrível marca de transportar quase um milhão e duzentos mil passageiros, tornando-se, assim, uma das maiores empresas aérea do país. As peripécias da vida de Rolim são contadas em inúmeros livros sobre marketing e em centenas de sites na Internet, como exemplo de espírito empreendedor. Mais um herói salta da vida cotidiana para entrar na história de um país.

\section{Storyteeling e história oficial}

Aliás, o que é um país senão uma série de histórias sob o ponto de vista de uma classe dominante, criando sistemas de pensamentos por meio de suas narrativas de vida? Foi esse mesmo sistema que consagrou os bandeirantes como heróis da pátria, escondendo o assassinato de milhares de índios; ou a escravidão dos negros, retirados de suas pátrias e do seu seio de suas famílias para depois serem vendidos, escravizados, humilhados e, posteriormente, atirados como objetos sem serventia no meio das ruas dos grandes centros urbanos. Os storytellings de nossos heróis estão sob o angulo de vista da elite dominante, dando às classes dominadas a impressão de que nossos heróis são quase sempre europeus ou deles descendentes. Assim, por exemplo, quem libertou o país do jugo português foram os próprios portugueses. Essas narrativas estereotipadas passam de geração a geração, sem questionamentos, principalmente no ensino público. É preciso reconhecer, porém, que já há certa mudança, embora, ainda tímida, nesse clima. 
Roland Barthes (1979) assegurou com contundência que a linguagem tem um poder fascista: "A língua implica uma relação fatal de alienação." (p. 13); [...] "o fascismo não é impedir de dizer, é obrigar a dizer." (p. 14): [...] "língua e discurso são indivisos, pois eles deslizam segundo o mesmo eixo de poder." (p. 31). Paradoxalmente, se por um lado a linguagem da narrativa pode impedir que o narratário veja além ou aquém das palavras, pois tudo aqui vira encantamento, ao atingir a emoção antes da razão, como na publicidade, por outro, há o leitor crítico que percebe a ideologia existente nas entrelinhas dadas. Tudo isso só pode ser feito por meio da linguagem da narrativa, verbal ou não. Quem narra mostra um lado do fato, tendendo a ocultar o outro, que fica apenas sugerido aos leitores críticos.

É preciso perceber, por exemplo, que as narrativas publicitárias não vendem um produto, mas um estilo de vida. Elas mostram o objeto à venda idealizado como sendo uma espécie de espada mágica, um passaporte para abrir as portas da vida perfeita ao seu possuidor. Por isso, a publicidade narra histórias de heróis dos esportes calçando um tênis de marca, por exemplo, como se, com outra, ele não tivesse a capacidade de realização que tem com essa; se o consumidor é um sujeito que pensa nos grandes problemas da atualidade, como o preconceito racial, por exemplo, ele veste as roupas da Benetton e assim por diante. Esses aparatos são objetos modais conforme o dicionário de semiótica de Greimas e Courtés (1984), ou seja, meios para atingir um objetivo outro: o objeto-valor. Servindose dos produtos idealizados nas narrativas, os seus consumidores se tornam vencedores, heróis. Eis aqui toda a trama não dita explicitamente nos discursos da publicidade.

Como o desafio das campanhas publicitárias atuais é atingir um público cada vez mais abrangente, a linguagem da publicidade tornou-se um storytelling conciso, com o mínimo de linguagem verbal, já que o código da língua não é tão universal como a imagem. $\mathrm{O}$ storytelling como publicidade passou a encarar como narrativa até mesmo o logo da empresa, como é o caso do Bradesco, em que dois semicírculos que se entrecruzam no espaço dão proteção ao grande e ao pequeno cliente, narrando assim essa interação; ou mesmo a história da construção das embalagens, como é o caso da garrafa da CocaCola, lembrando May West. Essa garrafinha sugere as curvas do corpo dessa atriz de cinema. Histórias como essas se tornaram conhecidas 
mundialmente e essa garrafa até se tornou um souvenir para seu público consumidor. A história da vida da própria empresa ou da vida de seus donos foi personificada nas publicidades, como foi o caso da Hering, contando a imigração dos seus donos e a fundação da fábrica no sul do Brasil, nos anos 90.

Essas narrativas passaram a mostrar ao público-alvo que o interessante para a empresa era servi-lo com um determinado produto que o tornasse completo, criando relações afetivas entre ela e esse público. A fidelização à marca aparece como um casamento bem realizado. Muito além do interesse da venda simples de um produto, a empresa passou a se envolver em questões sociais mais profundas, ligando seu nome à ecologia, à educação, às práticas esportivas, à melhoria da saúde, enfim, da vida de todos. Tudo se passa como se a empresa percebesse que esse público seria a sua "galinha dos ovos de ouro" e dar vida saudável a todas elas seria um meio de um convívio perfeito entre todos. Tudo essas estratégias, porém, escondem o objetivo verdadeiro da narrativa feita: fazer o homem se consumir ao consumir o produto, ou a idéia à venda.

\section{À guisa de conclusão}

Assim, storytellings vão ganhando a função de persuadir, para criar crenças e hábitos no público-alvo a ser consumido por ela. Foi assim que explodiram nas bancas revistas e livros pródigos a ensinar o sujeito a ter idéias para se auto-ajudar a vencer na vida. São milhares de receitas, vindas das mais diferentes fontes. Desde aquelas que apregoam religiões com milagres, bem como o exemplo da vida dos heróis olimpianos, que ditam regras de conduta e hábitos de vida, até a vida empreendedora de homens que saem do nada e atingem um patamar de relevância no cenário de um país.

Esse estudo do Storytelling, portanto, não está preocupado com o texto em si, como linguagem, tal como o estuda a semântica, a hermenêutica, a teoria literária, a lingüística, a narratologia, entre outras. Ele trata simplesmente do ato de comunicação de narrativas, principalmente pela mídia, com finalidades pragmáticas. Trata de mergulhar mais profundamente na relação de comunicação como o sujeito a ser conquistado, procurando atingir, principalmente, a sua inteligência emocional, que dá primazia e relevo ao instintivo, ao informal 
e ao irracional humanos, que estão aquém dos nossos conhecimentos conscientes. A publicidade sabe que se o sujeito raciocinar sobre o que vai comprar, em geral, a compra dificilmente se realiza. O marketing atua, então, primordialmente no psíquico do comprador. O princípio dessa relação é um storytelling de profundo poder de instinto, onde não se explica porque se deseja algo, de modo racional, mas sim, de modo emocional. Storytelling é um produto à venda, antes de mais nada.

O storytelling, portanto, segue a premissa que toda e qualquer história, sendo boa e narrada no momento adequado, dentro de um contexto propício a ela, conduz à certeza de sucesso do sujeito narrador. Desse modo, storytelling não é um texto narrado de modo simplório, como se narram histórias para entreter crianças, que acreditamos, também não ser ingênuo. É uma maneira subliminar de impor idéias. O storytelling é um modo espontâneo e fácil de recuperar o lado criança que existe em todo ser humano. Por esse meio, o narrador atinge objetivos outros que não o de propriamente dar conhecimento de determinado fato existente ou gerador da narrativa em si mesma. Por certo, esse texto como um storytelling ou meta-storytelling ainda há de dar muitos frutos, já que há muitos ângulos desse meio de comunicação de massa que ainda não foram abordados aqui.

\section{Referências}

ANDERSON, C. A Cauda Longa: do mercado de massa para o mercado de nicho Data de lançamento. São Paulo: Ed. Campus/ Elsevier, 2006.

BARTHES, R. Aula. São Paulo: Cultrix, 1979.

BAUMAN, Z. Amor Líquido: sobre a fragilidade dos laços humanos. Rio de Janeiro: Jorge Zahar, 2004.

BUONANNO, M. O teledrama como sistema central de narração de histórias na Itália contemporânea. Matrizes, Revista do Programa de Pós-graduação em Ciências da Comunicação da São Paulo, a. 1, n.1, p. 139-161, jul./dez. 2007. 
GREIMAS, A.J.; COURTÉS, J. Dicionário de Semiótica. São Paulo: Cultrix, 1984.

MOTA, M. Transmedia-Storytelling. Disponível em: <http:www.coxacreme.com.br>. Acesso em 10 jan. 2008.

SALMON C. Storytelling: la machine à fabriquer des histoires et à formater les esprits. Paris: La Découverte, 2007.

SUSCA, V. Nos limites do imaginário: o governador Schwarzenegger e os telepopulistas. Porto Alegre: Sulina, 2007.

SÁ, N. de. Políticos transformam internet em arma de campanha. Disponível em: <http://www1.folha.uol.com.br/folha/informatica/ ult124u20433.shtml>. Acesso em 22 jan. 2008. 